\title{
Evaluating electronic information services: a toolkit for practitioners
}

\author{
Stella Thebridge
}

\section{The author}

Stella Thebridge is a Research Fellow in the Centre for Information Research (CIRT) at the University of Central England in Birmingham (UCE) and a researcher on the eVALUEd project. She has researched and written about a range of projects involving public and academic libraries, the book trade and archives and museums. Prior to her move to the research sector, Stella worked in a range of public and academic libraries.

\section{Abstract}

As the eVALUEd project reaches the end of its research phase, this article seeks to inform practitioners about the development of the online toolkit which will provide help with the evaluation of Electronic Information Services (EIS). The background to the project and research results are described in order to set in context the development of the toolkit and its content. While the project stems from the Higher Education sector, it is hoped that many of the tools will be transferable to other sectors.

\section{Background - the eVALUEd project}

The thirty-month HEFCE-funded eVALUEd project (running since December 2001) has been concerned with the "examination of good practice in evaluation of electronic library initiatives in the UK and abroad, and testing of the techniques and practices identified". It was anticipated in the project proposal that this would "result in the production of an evaluation model for electronic library developments, transferable across the higher education sector". Much has now been written on the project's research phase, which included:

- a survey to all UK Higher Education Institutions to establish a baseline of evaluation activity relating to Electronic Information Services (EIS) (Thebridge et al, 2002)

- follow-up interviews (Hartland-Fox et al, 2002) and

- a review of the literature and current practice in relation to the sphere of outcomes assessment (Thebridge and Dalton, 2003).

The purpose of this article is to relate in more detail the development of the online toolkit, which started life as a proposed "model for the evaluation of digital libraries". It soon became clear that there could be no single all-encompassing model, but that a number of approaches would be required to cater for distinct and varied institutions, for different levels of EIS provision and for varied levels of evaluation and measurement skill among practitioners. Furthermore, the eVALUEd project's origins in the days when digital libraries were distinct and discrete entities from 'main' library services were shown to be unhelpful in the emergence of seamless print and electronic services across most of the HE sector. In other words it appeared that successful evaluation tools for EIS would be those that could link with existing measures for traditional library services as well as harnessing newly-emergent tools relating specifically to EIS. It would not be possible to provide a single system of evaluation for what had originally been project-based services. 


\section{Research results}

The research work, encapsulated in the survey, interviews and literature review revealed a number of useful facts about the level of evaluation activity in relation to EIS in Higher Education libraries and information services in the UK.

The following bullet points are key indicators of the current situation:

- The need for evaluation of EIS to take place is specified in few written policy statements

$77 \%$ of respondents to the survey did not have such a policy. This does not mean they were not undertaking evaluation, just that it was not written into strategy.

- The depth of evaluation varies considerably among academic library practitioners

32 respondents commented generally at the end of the questionnaire, mostly to explain their reasons for not having conducted as much evaluation as they would have liked to. These included descriptions of evaluation practice as "ad hoc and informal", "rough and ready", "tentative". Two comments were:

Can't say, however, that we evaluate print collections to the level suggested in some of these questions!

Systematic evaluation within the service is under-developed.

- Raw data, both supplier statistics and in-house data, are inadequate

Of the 54\% (61 institutions) who claimed to be using statistics, measures or standards to carry out their evaluation, a large number cited vendor usage statistics as their main or single statistical measure (28) and a further 27 specified usage statistics, which might also have been supplied by vendors or drawn from in-house data. At the same time, respondents commented consistently about the unreliability, lack of comparable data and inadequacy of vendor statistics across the board. For example, one noted:

We rely on management information statistics to tell us how well a resource is used, and we are aware that the statistics can only provide a very crude measure.

The implication is that, in the absence of any other measure, institutions are resorting to these data to evaluate their services.

- The main driving forces behind the need to evaluate EIS are showing value for money and identifying the library's contribution to institutional outcomes

Some interviewees mentioned the influence of factors external to the institution. These are cited below, with the bracketed number of individuals (from a total of 20 interviewed) referring to them:

- SCONUL statistics and electronic information service measures (9)

- Project COUNTER [Counting Online Usage of Networked Resources] (7) 
- Quality Assurance Agency [QAA] (3)

- Creation of a consortium with other institutions and/or organisations (2)

- Funders, e.g. Teaching Enhancement Quality Fund, Higher Education

Funding Council for England (HEFCE)] (2)

- The need for a comprehensive toolkit with information directed at all levels of user competence

81 institutions (72\%) confirmed that they would like support with their evaluation of EIS. Their suggestions for help ranged from specific areas, such as cost-benefit analysis, to general comments like "interested in reviewing current good practice in this area". As one commented:

I would also love to have the time to put together focus groups/questionnaires specifically for EIS. ... I would welcome standard formats for such surveys, as they would cut down on my work considerably.

A conclusive $95 \%$ of survey respondents (106 institutions) said that they would use a free evaluation toolkit if one were available, and 88\% (99 institutions) said they would welcome training opportunities in the evaluation of EIS. This is a useful endorsement of the main aims of the eVALUEd project.

The researchers were disappointed to find no mention in the survey of the use of specific measures, for example, the EQUINOX performance indicators for EIS. So in the follow-up interviews, respondents were asked about both the EQUINOX indicators and the e-metrics project of the Association of Research Libraries in the US to see if they had a) heard of these and $b$ ) were using the indicators. Of the 20 interviewees, eight had heard of EQUINOX (12 had not) and four had heard of ARL e-metrics (16 had not). No use was being made of emetrics and while two claimed to be using EQUINOX, they were adapting the indicators quite considerably. Those who were not using them felt them to be too prescriptive and in a framework that was not considered easy to use.

\section{Toolkit rationale}

Based on the information gathered from practitioners in the survey and interviews, the research team concluded that the toolkit should:

- be rigorous but not complicated

- enable longitudinal studies / the replication of surveys

- offer tools for different kinds of evaluation

- make use of and refer to existing tools.

As well as being encouraged to use data they already collect or which is latent, practitioners will be provided with tools and guidance to assist them in collecting the additional data required to evaluate particular aspects of EIS.

Information will be presented in the form of:

- Background information about each of the key areas for EIS evaluation

- Practical advice on carrying out self-evaluation 
- Sample questionnaires, interview and focus group schedules for various audiences, including library staff, academic staff and students

- Templates into which questions can be downloaded from different sources for customisation

- Support to assist libraries in the collection of statistical and documentary data

- Guidance on the analysis and usage of evaluation findings.

\section{Toolkit content}

Existing tools will be incorporated wherever possible. For example, in the following three areas, links will be made as shown:

- $\quad$ satisfaction surveys - SCONUL template [including examples of some institutions' adaptations]

- performance indicators - EQUINOX software [there is scope for further awareness and use of this, however, maintenance may become a problem]

- supplier statistics - project COUNTER code of practice [an initiative which brings publishers and libraries together to ensure the collection/provision of usage statistics in formats that will be comparable and relevant]

Links will be made to appropriate projects, web sites and printed materials. New tools will be offered in many areas, and Table 1 is a straightforward example of questions that might be asked of academic staff in relation to the impact of EIS on students' information literacy skills:

Table 1: Impact of EIS on students' information literacy skills - questions for academic staff

1. Do EIS-related information skills feature in all the courses you teach? For all years/levels?

2. How effectively are EIS-related information skills integrated into the curriculum?

- Are they clearly identified and broken down into component parts?

- Do they appear throughout the course/module (and are not simply narrowly located within study skills)?

- Are there opportunities for students to practise and reinforce skills?

3. Do EIS-related information skills form part of assessment schemes? Please give details.

4. Are EIS-related information skills taught in a way which reflects the range of different learning styles? Please give details.

5. What role do you play in the delivery of EIS-related information skills?

6. How do you work with library staff to do this?

7. Do you find that students are able to select those EIS resources which 'best fit' the task at hand?

8. Do students cite bibliographic references from EIS resources accurately in project reports and theses?

In the same area of impact of EIS on students' information literacy skills, the questions in Table 2 might be asked of students: 
Table 2: Impact of EIS on students' information literacy skills - questions for students

1. Which EIS resources have you used since the start of this semester? (Please tick all which apply)

Archives Bibliographic databases $\quad$ Book chapters

E-journals Exam papers IT services

Journal articlesMultimedia/AV materials

Official university documentation Pre-prints Reading lists

Skills modules Student projects Theses Other

2. Which resources have you found most useful? (Please list up to three, these may be types of resources or specific e-journals, databases etc)

3. Which are you most likely to use in the future? (Please list up to three, these may be types of resources or specific e-journals, databases etc)

4. Which EIS resources do you use when you want to find general background information? (These may be types of resources or specific e-journals, databases etc)

5. Which EIS resources do you use when you want to find detailed information? (These may be types of resources or specific e-journals, databases etc)

6. Which tools do you find most useful to locate relevant EIS information? E.g. searching, browsing, indexes. Please explain why these tools are particularly useful.

7. What do you do if a search produces too many results?

8. What do you do if a search produces too few results?

9. How do you ensure that the EIS resources you use are accurate and relevant?

10. Do you compare print and electronic resources?

What criteria do you use?

Table 3 is an example of a tool in a different area of evaluation, that of outcomes assessment. The eVALUEd researchers have identified eight areas from institutional and library mission statements and strategy documents in which libraries can seek to identify the contribution of EIS provision to the outcomes of their institution. These eight areas are:

- How EIS supports learning

- How EIS supports teaching

- How EIS supports research

- How EIS provides a range of resources

- The effectiveness of EIS provision

- How EIS collaborates internally and externally

- How EIS meets user needs

- How EIS supports staff career development 
Table 3 shows the suggested outcomes for the first of these areas, that is, 'learning', also giving examples of demonstrable evidence to support these outcomes and data collection methods:

Table 3: Outcomes assessment - support for learning

\begin{tabular}{|c|c|c|}
\hline $\begin{array}{l}\text { How EIS supports } \\
\text { learning }\end{array}$ & $\begin{array}{l}\text { Demonstrable evidence to support } \\
\text { outcomes (examples) }\end{array}$ & Data collection methods \\
\hline $\begin{array}{l}\text { Encourages the use } \\
\text { of new types of } \\
\text { learning resources }\end{array}$ & $\begin{array}{ll}\text { - } & \text { video, } \\
\text { - } & \text { multimedia, } \\
\text { - } & \text { on-line tutorials } \\
\text { - } & \text { Information Skills } \\
\text { - Newsletters } \\
\text { - Images }\end{array}$ & $\begin{array}{l}\text { Statistics (number of use of resources) } \\
\text { Requests for digitisation } \\
\text { Reading lists } \\
\text { Student questionnaire } \\
\text { References in course materials }\end{array}$ \\
\hline $\begin{array}{l}\text { Encourages } \\
\text { experimentation } \\
\text { with new methods } \\
\text { of learning/learning } \\
\text { strategies }\end{array}$ & $\begin{array}{l}\text { - } \quad \text { self-study materials } \\
\text { - Skills sessions }\end{array}$ & $\begin{array}{l}\text { Student questionnaire } \\
\text { References in course materials } \\
\text { EIS development policy giving rationale } \\
\text { for introduction of resources to support } \\
\text { different learning styles }\end{array}$ \\
\hline $\begin{array}{l}\text { Motivates students } \\
\text { to learn }\end{array}$ & 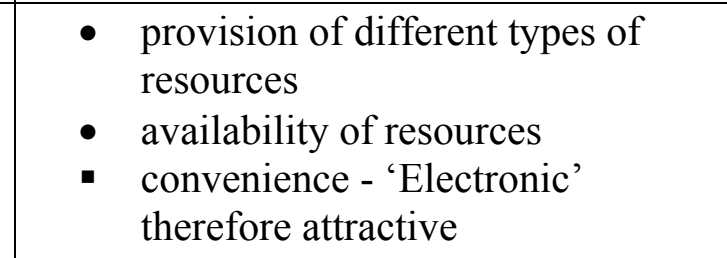 & $\begin{array}{l}\text { Student questionnaire } \\
\text { Results/reports of consultation exercises }\end{array}$ \\
\hline $\begin{array}{l}\text { Provides learning } \\
\text { resources }\end{array}$ & $\begin{array}{ll}\text { - } & \text { range of resources } \\
\text { - } & \text { quality of resources } \\
\text { - } & \text { number of resources (multiple } \\
\text { copies) }\end{array}$ & $\begin{array}{l}\text { Audit in terms of peer reviewed } \\
\text { resources, subject coverage, currency, } \\
\text { number of resources (/students on } \\
\text { course) }\end{array}$ \\
\hline $\begin{array}{l}\text { Meets the needs of } \\
\text { different types of } \\
\text { learners }\end{array}$ & $\begin{array}{l}\text { - by level, course, mode of study } \\
\text { - } \text { provision for people with different } \\
\text { learning styles } \\
\text { - disabilities/special needs e.g. } \\
\text { ESOL } \\
\text { - Providing students with skills to } \\
\text { access these resources }\end{array}$ & $\begin{array}{l}\text { Audit of resources by categories } \\
\text { Number of users in each category }\end{array}$ \\
\hline $\begin{array}{l}\text { Improves access to } \\
\text { resources }\end{array}$ & $\begin{array}{l}\text { - off campus } \\
\text { - out of hours } \\
\text { - matching delivery to needs of } \\
\text { - learners } \\
\text { / finding tools } \\
\text { - Making website a gateway to } \\
\text { Library resources }\end{array}$ & $\begin{array}{l}\text { Number of new users } \\
\text { Student questionnaire } \\
\text { Off campus access figures }\end{array}$ \\
\hline $\begin{array}{l}\text { Helps to improve } \\
\text { learning skills }\end{array}$ & $\begin{array}{l}\text { - information literacy skills } \\
\text { - ICT skills }\end{array}$ & $\begin{array}{l}\text { Training/help documentation } \\
\text { Student questionnaire }\end{array}$ \\
\hline
\end{tabular}


Piloting exercises are currently underway in a number of higher education institutions to assess material for the toolkit as well as looking at the site in prototype.

\section{Case studies}

There will also be a set of case studies presented on the toolkit. These comprise seven institutions that provide a summary of evaluation activity in relation to their EIS. There is no intention of presenting them as ideals or as the single way to carry out evaluation of EIS. Rather they present all their evaluation activity in its varying degrees of success. The purpose is to show the range of activities which can be carried out and the kinds of resources needed to undertake them. In some cases there are useful methodologies and evaluation instruments which can be used by other institutions.

The case studies represent a range of institutions. While the original eVALUEd project proposal aimed to investigate good practice, the situation is such that the research team has actually investigated practice per se, in other words any evidence of the evaluation of EIS. This means that there is no intention to set up ideals or models, but rather to give practical examples of what can be done - pitfalls and all. An interesting outcome of the case studies is the confirmation that institutions are keen to learn from each other. The provision of instruments and information on the eVALUEd toolkit will enable this to be carried out more quickly and uniformly across institutions.

\section{Toolkit style}

Much time has been given to the toolkit's design, including usability issues. Figure 1 shows the latest style. This has yet to be piloted and may undergo further amendments.

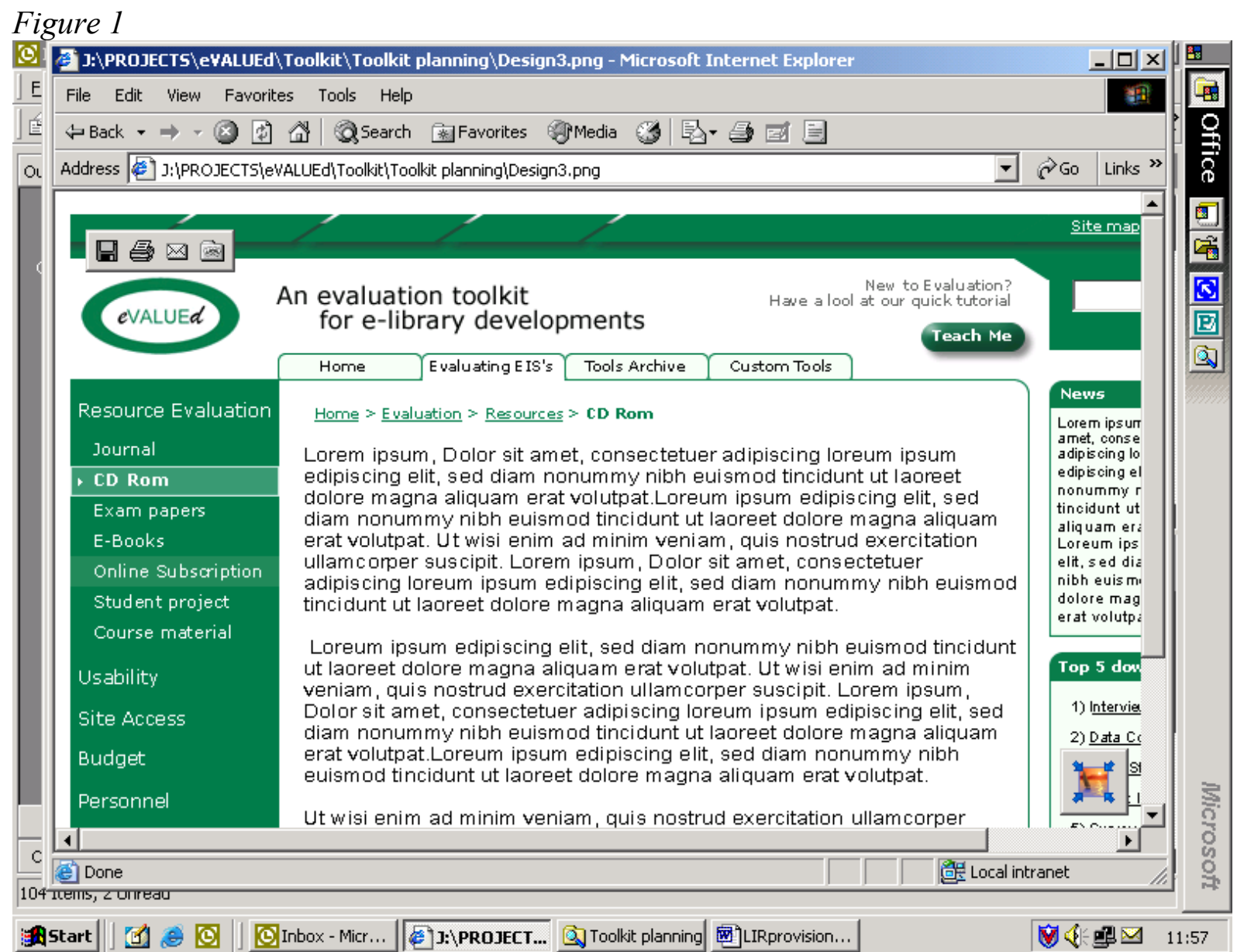


The site offers a tutorial [the 'Teach me' button - top right in Figure 1] which is a step-bystep introduction to the process of evaluation. This will include sections on: selecting a focus for an evaluation; choosing methods and tools; practical considerations; effective use of findings.

The three main sections of the site - on the 'index card' headings of Figure 1 - are:

1. Evaluating EIS

2. Tools archive

3. Custom tools.

1. The evaluating EIS section will cover the following sub-pages:

- Use and users

- Resources

- Access

- Management.

Each of these is then sub-divided at a third level as follows:

Users
Usage
Impact on users
User satisfaction
User support
Promotion

Each of these will be discussed by relevance to resource types, e.g. journal articles, examination papers, course materials [see the left-hand column on Figure 1].

Resources

Provision

Development

Access
Access to EIS
Technical aspects

\section{Management}

Outcomes assessment

Personnel

Budgeting

Collaboration and integration.

2. The Tools archive will contain:

- Case studies

- Checklists

- Interview and focus group questions 
- Survey questions

- Statistical data

- Document analysis

- Data collection forms

- Observation checklists.

3. The Custom tools will offer users the opportunity to customise survey instruments, along the lines of a shopping basket, enabling them to take whole instruments or parts of tools as they require and build them into a personalised evaluation instrument.

It should be emphasised that the toolkit's coverage has been described as in "breadth rather than depth" - in other words it may not be possible in the timescale to fill in all the detail for every section of the toolkit which the team would like to offer but there will at least be some preliminary material in every section of the toolkit to start practitioners off in their evaluation.

\section{The next step}

The aim is to provide an intuitive site (easy to get around), an interactive site (easy to customise to users' wants) and a site which practitioners can enter at a level appropriate to their job type and evaluation skills. The toolkit is scheduled to go live in the spring of 2004. It is hoped that some means can be found to keep the site not only live but actively maintained, otherwise its usefulness could reasonably be called into question.

As part of the project's remit, free workshops in the UK regions will be held in the summer and autumn of 2004 to raise awareness and help practitioners use the toolkit. However, the toolkit site will be freely available to all and will incorporate tutorials and help features.

Further funding has been granted by HEFCE to explore in depth the following two areas:

1. e-measures. Running until March 2005, this project aims to develop a new set of current performance measures for EIS in academic libraries and to work with SCONUL to pilot, refine and roll them out to the sector as standard performance measures for EIS.

2. Aligning institutional outcomes with library outcomes specifically in relation to EIS. This will involve more detailed approaches to outcomes assessment in academic libraries through case studies.

Some updating of the eVALUEd site will be included in this follow-on work.

\section{References}

All website references were live in September 2003.

\section{Projects and organisations}

\section{COUNTER}

(Counting Online Usage of Networked Electronic Resources)

(Available at: http://www.projectcounter.org/index.html)

\section{EQUINOX}

Library Performance Measurement and Quality Management System 
Performance Indicators for Electronic Library Services

(Available at: http://equinox.dcu.ie/reports/pilist.html)

eVALUEd - evaluation toolkit for e-library developments

(website is at: http://www.cie.uce.ac.uk/evalued/)

\section{HEFCE}

(Higher Education Funding Council for England)

(Available at: http://www.hefce.ac.uk/)

SCONUL (Society of College, National and University Libraries)

The SCONUL Advisory Committee on Performance Improvement (SCONUL ACPI) is at http://www.sconul.ac.uk/performance ind/terms.htm

\section{Texts}

Hartland-Fox, R, Dalton, P, Thebridge, S and Bhatt, A (2002)

eVALUEd questionnaire follow-up interviews with library managers and selected personnel. eVALUEd Project Paper 3. (Available at:

http://www.cie.uce.ac.uk/evalued/Library/Paper3 Interviews.pdf)

Thebridge, S and Dalton, P (2003)

'Working towards outcomes assessment in UK academic libraries', Journal of Library and Information Science, 35 (2) June p 93-104

Thebridge, S, Dalton, P, Hartland-Fox, R and Bhatt, A (2002)

Questionnaire to Higher Education Institutions in the UK: analysis of responses. eVALUEd Project Paper 1. Available at:

http://www.cie.uce.ac.uk/evalued/Library/Paper1_QuAnalysis.pdf 